\title{
Neurocognitive Functions in Soacial Anxiety Disorder
}

\author{
Deniz Deniz Özturan ${ }^{1}$, Hatice Özyıldız Güz², Ahmet Rıfat Şahin² ${ }^{2}$ Ali Cezmi Arık², Ömer Böke², \\ Gökhan Sarısoy ${ }^{2}$, Ozan Pazvantoğlu ${ }^{3}$ \\ ${ }^{1}$ Ordu University, Faculty of Medicine Department of Psychiatry Ordu,Turkey \\ ${ }^{2}$ Ondokuz Mayis University Faculty of Medicine Department of Psychiatry. Samsun, Turkey \\ ${ }^{3}$ Sokrates Medical Center, Department of Psychiatry, İzmir, Turkey \\ Received: 18 January 2020, Accepted: 26 August 2020, Published online: 31 August 2020 \\ (C) Ordu University Institute of Health Sciences, Turkey, 2020
}

\begin{abstract}
Objective: The purpose of this study was to assess the neurocognitive functions of patients with social phobia and to examine the relation between these functions and the severity of the disease.

Methods: The study was performed with 30 patients under monitoring with a diagnosis of social phobia at the Ondokuz Mayis University Psychiatry Clinic and 30 age- and sex-matched healthy controls. Patients were assessed using the Hamilton Anxiety Rating Scale (HARS), the State-Trait Anxiety Inventory (STAI), and the Liebowitz Social Anxiety Scale (LSAS). Both groups were administered the Wisconsin Card Sorting Test (WCST), the Stroop Test, the Auditory-Verbal Learning Test (AVLT), and the Trail Making Test (TMT) forms A and B, and the two groups' neurocognitive performances were compared.

Results: Social phobia patients exhibited significantly poorer performance than the control group in terms of total number of errors, number of perseverative errors and number of categories completed on the WCST, time taken to complete TMT forms A and B, time taken to complete the first, third, fourth and fifth parts of the Stroop test, and AVLT immediate recall scores. Positive correlation was determined in the patient group between LSAS subscores and time taken to complete the first, third and fourth parts of the Stroop test. Positive correlation was also determined between patients' time taken to complete the fifth part of the Stroop test and LSAS avoidance and total scores.

Conclusion: Greater impairment was observed in the attention, executive function and immediate recall performances of social phobia patients compared to the healthy controls.
\end{abstract}

Key words: Social phobia, Neurocognitive functions, memory

Suggested Citation: Deniz Ozturan D, Ozyıldız Guz H, Sahin AR, Arik AC, Boke O, Sarisoy G, Pazvantoglu O. Neurocognitive Functions in Soacial Anxiety Disorder. Middle Black Sea Journal of Health Science, 2020; 6(2):249-256

\section{Address for correspondence/reprints:}

Deniz Deniz Özturan

Telephone number: +90 (452) 2265214

ORCID-ID 0000-0003-3889-3652

E-mail: dr.denizdeniz@gmail.com

DOI: $10.19127 / \mathrm{mbsjohs.676960}$

\section{Introduction}

Social anxiety disorder is a pronounced and constant fear of one or more social performance situations that may cause embarrassment (APA, 2000). Individuals with social anxiety disorder experience problems in working life, education, and social and emotional relations. Patients who fear and avoid one or only a few social situations are defined as having 'specific type' social phobia, while those who fear and avoid several social situations are defined as having 'generalized type' social phobia (APA, 1994). In DSM-V generalized specifier deleted (APA, 2013). In terms of studies investigating neurocognitive functions in anxiety 
disorders, few have investigated cognitive functions in patients with social phobia, although this is a mental disease that is frequently seen and that causes severe disability.

Studies investigating the neurobiological aspect of social phobia concentrate on neurotransmitter systems and functioning problems in these systems. The relation between the neurotransmitter's serotonin and dopamine and social anxiety has been examined (Marcin and Nemeroff 2003; Kim and Gorman, 2005). Tiihonen et al. (1997) concluded that since dopamine reuptake site densities in the striata of patients with social phobia were significantly lower compared to those in healthy individuals, social phobia is related to dopamine function disturbance. In their magnetic resonance spectroscopy study, Davidson et al. determined an increase in central nervous system activity in the zones of the basal ganglia, white matter, and other cortical or non-cortical gray matter (Davidson, 1993a). In contrast, Potts et al. observed no significant difference between social phobia patients and age- and sex-matched healthy controls in terms of caudate, putamen, thalamus and cerebral volume (Potts et al., 2003). Another study employing cerebral imaging of subjects with social phobia observed increased blood flow in the right dorsolateral prefrontal cortex, the left inferior temporal cortex and the left amygdaloidalhippocampal region (Tillfors et al., 2001). One study which evaluated social phobia and control group cortex thicknesses using magnetic resonance determined thinning in the frontal, temporal, parietal and insular cortexes, which play important roles in executive, social and emotional functions, in patients with social phobia (Syal, 2012). This study evaluated neurocognitive functions in patients with generalized social phobia and examined various factors that might be associated with cognitive functions.

\section{Methods}

Volunteers meeting the study criteria were enrolled from among patients diagnosed with generalized social phobia and receiving treatment for at least one month at the Ondokuz Mayis University Medical Faculty Psychiatric Clinic. We anticipated that patients with generalized type social phobia, who experience greater loss of function than patients with specific type social phobia, would also have greater impairment of neurocognitive functions. Patients meeting a diagnosis of generalized type social phobia were therefore enrolled in order to produce a homogeneous group. We aimed to enroll 30 patients and 30 healthy controls, by calculating power analysis, and enrolment was stopped when these numbers were achieved. The patients have no psychiatric comorbidity. Healthy volunteers matched to the patient group in terms of age and sex and consisting of hospital personnel and university students were included as the control group. In the first session, the patients were administered SCID-V, a structured clinical interview, in order to determines Axis-I psychiatric disorders according to DSM-V. Additional diagnoses were excluded, and patients with Liebowitz Social Anxiety Scale (LSAS) scores over 60 were asked to complete a sociodemographic data form, and these patients were assessed in the second session. In the second session, the patients were administered the Hamilton Anxiety Rating Scale (HAM-A), the State-Trait Anxiety Inventory (STAI) and the LSAS. Once the tests were completed, neuropsychological test battery was applied consisting of the Wisconsin Card Sorting Test (WCST), the Stroop Test, the Auditory-Verbal Learning Test (AVLT), and the Trail Making Test (TMT) forms A and B. The neuropsychological tests applied to the patient group were also administered to the control group to compare the findings obtained. The aim and methodology of the study were explained to all participants, and verbal and written consents were obtained. The study protocol was approved by the Ethic Committee for Clinical Research Ondokuz Mayıs Medical Faculty (Date: 24.10.2011). This article is derived from the Republic of Turkey, our thesis registered with expertice in the national thesis center number 340551.

\section{Data collection tools}

Sociodemographic and Clinical Assessment Form: Separate forms for the patient and control groups were prepared by the authors to record information concerning sociodemographic and clinical characteristics.

The Structured Clinical Interview for DSM-V Axis I Disorders (SCID-V): A clinical interview developed for the diagnosis of major disorders according to DSM-V (First, 2015). The validity and reliability of the Turkish language version have been confirmed (Elbir, 2019).

Hamilton Anxiety Rating Scale: The validity and reliability of the Turkish language version were confirmed by Yazic1 et al. (1998).

The State-Trait Anxiety Inventory: The validity and reliability in Turkey were confirmed 
by Öner and Le Compte in 1985 (Oner and Le Compte, 1985).

Liebowitz Social Anxiety Scale: The validity and reliability of the Turkish language version have been confirmed (Dilbaz and Guz, 2001).

The Stroop test: The Stroop test TBAG (Basic Sciences Research Group) form was used in this study. The Stroop test is regarded as being particularly related to orbitofrontal cortex functions (Karakas, 2006).

Wisconsin Card Sorting Test (WCST): Originally developed by Berg in 1948, modifications were made by Heaton et al. in 1981 and 1993, and a test handbook was produced (Heaton, 1993). Our study used the total number of correct scores, total number of errors, number of categories completed, number of perseverative errors and number of non-perseverative errors, which have been frequently employed in previous studies.

Auditory-Verbal Learning Test (AVLT): The AVLT is easy to apply and score and permits examination of memory from various perspectives (Karakas and Kafadar, 1999).

Trail Making Test Forms $A$ and $B$ (TMT-A, TMT-B): The TMT was developed by Reitan (1958). This test provides information concerning mental flexibility, visual scanning, processing speed and cognitive functions.

\section{Statistical Analysis}

The data obtained from the study groups were transferred onto SPSS for Windows 15.0 software for statistical analysis. Whether the relation between dependent variable and other independent variables was normally distributed was evaluated according to Kolmogorov-Simirnov histogram and Q-Q Plots graph. Student's t test was used to compare age, length of education and neurocognitive test scores between the groups, and the chi square test, and Fisher's exact chi square test when required, in the comparison of grouped data. $\mathrm{p}<0.05$ was regarded as statistically significant. In the patient group neurocognitive test and LSA scale scores analysis was done using Pearson Correlation.

\section{Results}

Sociodemographic characteristics of the patient and control groups

No statistically significant difference was determined between the patient and control groups in terms of sex, age, length of education, marital status or place of residence (Table 1).
Clinical characteristics of the patient group

Age at onset of disease in the patient group was $15.70 \pm 3.42$ years, total duration of disease was $9.40 \pm 5.23$ years, untreated duration of disease was $5.53 \pm 3.62$ years and duration of most recent treatment was $6.33 \pm 5.70$ months. Mean LSAS anxiety score was $42.43 \pm 9.08$, mean LSAS avoidance score was $37.63 \pm 7.74$, and mean total LSAS score was $80.06 \pm 15.98$. Mean HARS score was $10.30 \pm 3.65$, mean STAI score was $40.27 \pm 13.24$, and mean Trait Anxiety Inventory score was $51.80 \pm 11.09$. In addition, 10 patients (33.3\%) in the patient group were diagnosed with avoidant personality disorder in addition to social phobia.

Comparison of Patient and Control group Neurocognitive Test Scores

Evaluation of WCST subscores revealed significant differences between the groups in terms of mean scores for total number of errors $(t=3.62$, $\mathrm{p}=0.001)$, numbers of perseverative errors $(\mathrm{t}=3.19$, $\mathrm{p}=0.002)$ and non-perseverative errors $(\mathrm{t}=3.32$, $\mathrm{p}=0.002)$ and number of completed categories $(\mathrm{t}=-$ 2.75, $\mathrm{p}=0.008$ ). Mean total error, perseverative error and non-perseverative error numbers were high in the patient group, while the mean number of categories completed was low. Differences were observed between the two groups in terms of time taken to complete the TMT forms A $(t=3.20$, $\mathrm{p}=0.002)$ and $\mathrm{B}(\mathrm{t}=4.26, \mathrm{p}=0.000)$. Patient group forms $\mathrm{A}$ and $\mathrm{B}$ were completed in a longer time than in the control group. Differences were also observed between the groups in terms of time taken to complete the first $(\mathrm{t}=2.96, \mathrm{p}=0.004)$, third $(\mathrm{t}=2.78, \mathrm{p}=0.007)$, fourth $(\mathrm{t}=3.46, \mathrm{p}=0.001)$ and fifth $(t=3.23, p=0.002)$ parts of the Stroop test, all being longer in the patient group. The only difference between the groups at comparison of AVLT scores was in immediate recall scores $(\mathrm{t}=-$ 2.36, $\mathrm{p}=0.022)$, which were lower in the patient group (Table 2).

Relations between LSAS Scores and Neurocognitive Test Scores in the Patient Group LSAS scores in the patient group were not correlated with WCST scores or time taken to complete TMT forms A and B. A weak-moderate positive correlation was observed between mean LSAS anxiety $(\mathrm{r}=0.451, \mathrm{p}=0.012)$, avoidance $(\mathrm{r}=0.440, \mathrm{p}=0.015)$ and total scores $(\mathrm{r}=0.469$, $\mathrm{p}=0.009)$ and time taken to complete the first part of the Stroop test. Weak-moderate positive correlation was observed between time taken to complete the third part of the Stroop test and mean LSAS anxiety $(r=0.479, p=0.007)$ score, while 
good positive correlation was determined with mean LSAS avoidance and $(\mathrm{r}=0.615, \mathrm{p}=0.000)$ total LSAS scores $(r=0.570, p=0.001)$. In addition, good positive correlation was observed between mean LSAS anxiety $(\mathrm{r}=0.578, \mathrm{p}=0.001)$, avoidance $(\mathrm{r}=0.735, \mathrm{p}=0.000)$ and total scores $(\mathrm{r}=0.684$, $\mathrm{p}=0.000$ ) and time taken to complete the fourth part of the Stroop test. Time taken to complete the fifth part of the Stroop test exhibited good positive correlation with mean LSAS avoidance scores $(\mathrm{r}=0.522, \mathrm{p}=0.003)$, and weak-moderate positive correlation with mean total LSAS scores $(\mathrm{r}=0.424$, $\mathrm{p}=0.020$ ). Analysis of correlation between mean AVLT subscores and mean LSAS scores revealed only a weak-moderate inverse correlation between mean verbal learning scores and mean LSAS anxiety $(\mathrm{r}=0.438, \mathrm{p}=0.016)$, avoidance $(\mathrm{r}=-0.453$, $\mathrm{p}=0.012)$ and total scores $(\mathrm{r}=-0.468, \mathrm{p}=0.009)$ (Table 3).

Table 1. A Comparison of the Patient and Control Groups in Terms of Sociodemographic Characteristics

\begin{tabular}{|c|c|c|c|c|c|}
\hline & & Patient $(n=30)$ & Control $(n=30)$ & Analysis & $\mathrm{p}$ \\
\hline \multirow[t]{2}{*}{ Sex } & Female & $15(50 \%)$ & $15(50 \%)$ & \multirow{2}{*}{$\mathrm{X}^{2}=0.000^{*}$} & \multirow{2}{*}{1.000} \\
\hline & Male & $15(50 \%)$ & $15(50 \%)$ & & \\
\hline Age (years) & Mean \pm SD & $25.10 \pm 6.43$ & $25.70 \pm 5.23$ & $\mathrm{t}=-0.397 * *$ & 0.693 \\
\hline Length of education (years) & Mean \pm SD & $12.30 \pm 1.99$ & $12.97 \pm 2.87$ & $t=-1.046$ & 0.300 \\
\hline \multirow[t]{2}{*}{ Marital status } & Married & $8(26.7 \%)$ & $14(46.7 \$)$ & \multirow{2}{*}{$X^{2}=1.794$} & \multirow{2}{*}{0.180} \\
\hline & Unmarried & $22(73.3 \%)$ & $16(53.3 \%)$ & & \\
\hline \multirow[t]{2}{*}{ Place of residence } & Urban & $27(90 \%)$ & $28(92.3 \%)$ & \multirow{2}{*}{$* * *$} & \multirow{2}{*}{1.000} \\
\hline & Rural & $3(10 \%)$ & $2(7.7 \%)$ & & \\
\hline
\end{tabular}

*Chi square test, ${ }^{* *}$ Student $\mathrm{t}$ test, $* * *$ Using Fisher's exact chi square test.

Table 2. A Comparison of patient and Control Group Neurocognitive Test Scores

\begin{tabular}{|c|c|c|c|c|c|}
\hline & & $\begin{array}{l}\text { Patient } \\
(\mathrm{n}=30) \\
(\text { Mean } \pm \mathrm{SD})\end{array}$ & $\begin{array}{l}\text { Control (n30) } \\
(\text { Mean } \pm \text { SD }\end{array}$ & $\mathrm{t}$ & $\mathrm{p}$ \\
\hline \multirow{5}{*}{ W C S T } & Total number correct answers & $69.67 \pm 12.18$ & $72.43 \pm 9.28$ & -0.99 & 0.327 \\
\hline & Total number of errors & $39.50 \pm 23.87$ & $21.23 \pm 13.96$ & 3.62 & 0.001 \\
\hline & Number of perseverative errors & $18.60 \pm 11.02$ & $11.00 \pm 7.03$ & 3.19 & 0.002 \\
\hline & $\begin{array}{l}\text { Total number of non-perseverative } \\
\text { errors }\end{array}$ & $20.90 \pm 15.50$ & $10.23 \pm 8.29$ & 3.32 & 0.002 \\
\hline & Number of categories completed & $4.40 \pm 1.99$ & $5.57 \pm 1.19$ & -2.75 & 0.008 \\
\hline \multirow{2}{*}{ T M T } & Time $(\mathrm{sec})$ & $35.03 \pm 15.87$ & $24.70 \pm 7.88$ & 3.20 & 0.002 \\
\hline & Time (sec) & $76.98 \pm 33.11$ & $48.78 \pm 14.70$ & 4.26 & $<0.001$ \\
\hline \multirow{4}{*}{ A V L T } & Immediate recall & $6.23 \pm 1.63$ & $7.23 \pm 1.65$ & -2.36 & 0.022 \\
\hline & Verbal leaning & $48.37 \pm 7.39$ & $51.77 \pm 6.13$ & -1.94 & 0.057 \\
\hline & Retention & $10.57 \pm 2.08$ & $10.97 \pm 1.45$ & -0.86 & 0.391 \\
\hline & Delayed recall & $10.27 \pm 1.89$ & $10.73 \pm 1.68$ & -1.01 & 0.317 \\
\hline
\end{tabular}

Student $t$ test 
Table 3. Correlation between LSAS and Neurocognitive Test Scores in the Patient Group *

\begin{tabular}{|c|c|c|c|c|c|c|}
\hline & \multicolumn{4}{|c|}{ Liebowitz Social Anxiety Scale } \\
\hline & & & \multicolumn{2}{|c|}{ LSAS Anxiety } & \multirow{2}{*}{$\begin{array}{c}\text { LSAS Avoidance } \\
-0.215 \\
\end{array}$} & \multirow{2}{*}{$\frac{\text { LSAS Total }}{-0.132}$} \\
\hline \multirow{10}{*}{ W C S T } & \multirow{2}{*}{\multicolumn{2}{|c|}{ Total number of correct answers }} & $\mathrm{r}$ & -0.049 & & \\
\hline & & & $\mathrm{p}$ & 0.795 & 0.253 & 0.485 \\
\hline & \multirow{2}{*}{\multicolumn{2}{|c|}{ Total number of errors }} & $\mathrm{r}$ & 0.172 & 0.256 & 0.222 \\
\hline & & & $\mathrm{p}$ & 0.362 & 0.172 & 0.238 \\
\hline & \multirow{2}{*}{\multicolumn{2}{|c|}{ Number of perseverative errors }} & $\mathrm{r}$ & 0.248 & 0.322 & 0.297 \\
\hline & & & $\mathrm{p}$ & 0.187 & 0.082 & 0.111 \\
\hline & \multirow{2}{*}{\multicolumn{2}{|c|}{ Number of non-perseverative errors }} & $\mathrm{r}$ & 0.089 & 0.166 & 0.131 \\
\hline & & & $\mathrm{p}$ & 0.638 & 0.381 & 0.490 \\
\hline & \multirow{2}{*}{\multicolumn{2}{|c|}{ Number of categories completed }} & $\mathrm{r}$ & -0.294 & -0.355 & -0.339 \\
\hline & & & $\mathrm{p}$ & 0.115 & 0.055 & 0.067 \\
\hline \multirow{4}{*}{ T M T } & \multirow{2}{*}{\multicolumn{2}{|c|}{ A Form }} & $\mathrm{r}$ & 0.096 & 0.118 & 0.112 \\
\hline & & & $\mathrm{p}$ & 0.613 & 0.534 & 0.556 \\
\hline & \multirow{2}{*}{\multicolumn{2}{|c|}{ B Form }} & $\mathrm{r}$ & 0.118 & 0.245 & 0.186 \\
\hline & & & $\mathrm{p}$ & 0.535 & 0.193 & 0.326 \\
\hline \multirow{10}{*}{ S T R O OP } & \multirow{2}{*}{ Part 1} & \multirow{2}{*}{ Time (sec) } & $\mathrm{r}$ & 0.451 & 0.440 & 0.469 \\
\hline & & & $\mathrm{p}$ & 0.012 & 0.015 & 0.009 \\
\hline & \multirow{2}{*}{ Part 2} & \multirow{2}{*}{ Time (sec) } & $\mathrm{r}$ & 0.229 & 0.320 & 0.286 \\
\hline & & & $\mathrm{p}$ & 0.223 & 0.084 & 0.126 \\
\hline & \multirow{2}{*}{ Part 3} & \multirow{2}{*}{ Time (sec) } & $\mathrm{r}$ & 0.479 & 0.615 & 0.570 \\
\hline & & & $\mathrm{p}$ & 0.007 & $<0.001$ & 0.001 \\
\hline & \multirow{2}{*}{ Part 4} & \multirow{2}{*}{ Time (sec) } & $\mathrm{r}$ & 0.578 & 0.735 & 0.684 \\
\hline & & & $\mathrm{p}$ & 0.001 & $<0.001$ & $<0.001$ \\
\hline & \multirow{2}{*}{ Part 5} & \multirow{2}{*}{ Time (sec) } & $\mathrm{r}$ & 0.301 & 0.522 & 0.424 \\
\hline & & & $\mathrm{p}$ & 0.106 & 0.003 & 0.020 \\
\hline \multirow{8}{*}{ A V L T } & \multirow{2}{*}{\multicolumn{2}{|c|}{ Immediate recall }} & $\mathrm{r}$ & -0.342 & -0.288 & -0.334 \\
\hline & & & $\mathrm{p}$ & 0.064 & 0.123 & 0.072 \\
\hline & \multirow{2}{*}{\multicolumn{2}{|c|}{ Verbal learning }} & $\mathrm{r}$ & -0.438 & -0.453 & -0.468 \\
\hline & & & $\mathrm{p}$ & 0.016 & 0.012 & 0.009 \\
\hline & \multirow{2}{*}{\multicolumn{2}{|c|}{ Retention }} & $\mathrm{r}$ & -0.320 & -0.342 & -0.348 \\
\hline & & & $\mathrm{p}$ & 0.084 & 0.064 & 0.060 \\
\hline & D & & $\mathrm{r}$ & -0.312 & -0.356 & -0.350 \\
\hline & Delayed & & $\mathrm{p}$ & 0.093 & 0.054 & 0.058 \\
\hline
\end{tabular}

\section{*Pearson Corelation Test}

\section{Discussion}

Our study compared patients with social anxiety disorder and healthy controls in terms of neurocognitive test performances. It also examined whether severity of disease was correlated with neurocognitive test performances in patients with social anxiety disorder.

The AVLT was used to assess memory functions. Memory scores such as immediate recall, verbal learning, retention and delayed recall were evaluated using the AVLT. Mean immediate recall scores were lower in the patient group than in the control group. No statistically significant difference was determined between the two groups in terms of verbal learning, retention and delayed recalled subscores. Asmundson et al. (1994) compared age-, sex- and education-levelmatched patients, 18 with generalized social phobia, and 18 with panic disorder, and 16 healthy controls. Untreated patients were selected in that study, and the groups' verbal learning and recall performances were assessed using the California Verbal Learning Test. Immediate and long-term memory performances were lower in both the panic disorder and social phobia patients compared with the control group.

Airaksinen et al. (2004) compared cognitive functions in 33 patients diagnosed with social phobia, seven with generalized anxiety disorder, 16 with obsessive compulsive disorder (OCD), 33 with panic 
disorder (with/without agoraphobia) and 24 with specific phobia with those of healthy controls. They determined impairment in recall performance of patients with social phobia, with or without cues. Other studies have reported no memory impairment in patients with social anxiety disorder. Wenzel and Holt (2002) showed that when social phobia patients were read paragraphs with neutral content they exhibited the same level of recall as a healthy control group. Sachs et al. (2004) assessed verbal and nonverbal memory functions in social phobia patients and a healthy control group and showed no compromise of memory function in the social phobia patients. Another study evaluated memory functions in untreated patients with generalized type social phobia and a healthy control group using the Wechsler Memory Test and determined no difference between the two groups (Sutterby and Bedwell, 2012). Another study of memory function in patients with generalized type social phobia using the AVLT also determined no impairment of verbal memory functions in the social phobia patients (Fujii et al., 2013). Differences in the measurement tools used and sampling in studies can affect the findings and lead to inconsistent results being obtained. Williams et al. (1997) reported that individuals with anxiety directed their attention toward threat containing information and that this led them to prioritize such information. Since patients with social anxiety disorder direct their attention to threat containing stimuli when they enter a new environment, they may find it difficult to learn new information. This may also explain the impaired immediate recall in our study. The existence of conflicting findings concerning memory functions in social anxiety disorder shows that further studies are now needed to determine whether a problem exists in memory functions in these patients.

When we compared WCST subscores between the patients with social anxiety disorder and the controls, we observed differences in terms of mean total number of errors, number of perseverative errors, and numbers of categories completed. The WCST performances of the patients in our study were more impaired than those of the control group. We used the TMT in addition to the WCST to assess executive functions in our study. One previous study showed that TMT form B determined cognitive flexibility better than the WCST (Kortte et al., 2002). According to our findings, patients took longer to complete form $\mathrm{B}$ and exhibited a poorer performance on this test than the control group. Topçuoglu et al. (2009) compared the executive functions of social phobia patients with a healthy control group and concluded the executive functions by WCST. Our findings are compatible with that study. Cohen et al. used TMT form B to evaluate executive functions in 65 patients with OCD, 17 with social phobia and 32 healthy controls. They reported longer TMT form B completion times in the social phobia patients compared to the OCD and control groups. These findings are compatible with our study showing impairment in executive functions in patients with social anxiety disorder using TMT form B and the WCST. Another study that evaluated executive functions in social phobia patients using TMT form B enrolled 25 patients with generalized type social phobia and 25 healthy controls. Comorbid psychiatric diseases, with the exception of specific phobia, were excluded. No difference was determined between the groups in terms of TMT form B performances in that study (Sachs et al., 2004). Finally, Fujii et al. (2013) assessed the executive functions of 30 generalized type social phobia patients with no comorbid psychiatric disease using TMT-B and the WCST and reported no impairment of executive functions in the social phobia patients. Cognitive functions involved in social skills include planning, suppression of inappropriate alternatives among different response options, and deciding on the correct option. This shows that executive functions are necessary for an effective social performance. The fact that social phobia patients experience difficulties in establishing social relations may derive from impairment of executive functions. Our findings also support the idea of compromise of executive functions in these patients.

An inverse correlation was determined in this study between LSAS anxiety, avoidance and total scores and verbal learning scores. Patients with higher LSAS anxiety, avoidance and total scores taking longer to complete parts 1, 3, 4 and 5 of the Stroop test no correlation being observed between LSAS scores and time to complete form A, which measures attention, may be interpreted as meaning that severity of the disease is related to selective attention in particular. The absence of any relation between patients' social anxiety levels and time taken to complete TMT-B and the WCST suggests that severity of disease is not related to executive functions. However, the results of our study also showed that social phobia patients who took longer to complete part 5 of the Stroop test also had higher LSAS avoidance and total anxiety scores. In contrast to our study, TopçuoGlu et al. (2009) reported an inverse correlation between social anxiety and WCST results. Similarly, in a recent study, Topçuoğlu et al. determined a decrease in WCST performance and LSAS total scores and reported an inverse correlation 
between disease severity and executive functions (Sutterby and Bedwell, 2012).

All the patients in our study were using drugs from the selective serotonin reuptake inhibitor (SSRI) group. Since the patients in our study were not all using the same SSRIs, the differences between them may have had different effects on neurocognitive tests. Another limitation of our study is that the effect of patients' performance anxiety on neurocognitive test performance could not be entirely excluded.

\section{Conclusion}

In our study greater impairment was observed in the attention, executive function and immediate recall performances of social phobia patients compared to the healthy controls. Further studies are needed to show whether there is any association between neurocognitive test performance and drug effects

Ethics Committee Approval: The study protocol was approved by the Ethic Committee for Clinical Research Ondokuz Mayis Medical Faculty (Date: 24.10.2011). This article is derived from the Republic of Turkey, our thesis registered with expertice in the national thesis center number 340551.

Peer-review: Externally peer-reviewed.

Author Contributions: Concept. D.D.O, DesignD.D.O, H.O.G, Materials-.D.D.O, H.O.G, A.R.S, A.C.A, O.B., G.S., O.P.,Data Collection and Processing. D.D.O, H.O.G., G.S, Literature Review-. D.D.O., H.O.G., Writing- D.D.O, H.O.G, A.R.S, A.C.A, O.B., G.S., O.P.,Critical Review. D.D.O, H.O.G, A.R.S, A.C.A, O.B., G.S., O.P.

Conflict of Interest: No conflict of interest was declared by the authors.

Financial Disclosure: The authors declared that this study hasn't received no financial support.

\section{References}

Airaksinen E, Larsson M, Forsel $\mathrm{Y}$. Neuropsychological functions in anxiety disorders in population-based samples: Evidence of episodic memory dysfunction. Journal of Psychiatric Research 2004; 39: 207-214.

American Psychiatric Association, Diagnostic and Statistical Manual of Mental Disorders. 4th ed. Text Revision. (DSM-IV-TR). Washington DC: APA, 2000.

American Psychiatric Association, Diagnostic and Statistical Manual of Mental Disorders. 4th ed. (DSM-IV). Washington DC: APA, 1994.
American Psychiatric Association, Diagnostic and Statistical Manual for Mental Disorders. 5th edition (DSM-5). Washington DC: APA, 2013.

Asmundson GJ, Stein MB, Larsen DK, Walker JR. Neurocognitive function in panic disorder and social phobia patients. Anxiety. 1994; 1(5):201-7.

Cohen LJ, Hollander E, DeCaria CM, Stein DJ, Simeon D, Liebowitz MR. Specificity of neuropsychological impairment in obsessivecompulsive disorder: A comparison with social phobic and control subjects. Journal of Neuropsychiatry and Clinical Neuroscience. 1996; 8: 82-85.

Davidson JR, Krishnan KR, Charles HC, Boyko O, Potts NL, Ford SM, Patterson L. Magnetic resonance spectroscopy in social phobia: preliminary findings. J Clin Psychiatry 1993a; 54:19-25.

Dilbaz N., Guz H Liebowitz Social Anxiety Scale: The validity and reliability of the Turkish language version.37. National Psychiatry Congress, Istanbul, 2-6 October 2001.

Elbir M, Alp Topbas O, Bayad S, Kocabas T, Topak OZ, Cetin S, Ozdel O, Atesci F, Aydemir O. Adaptation and Reliability of the Structured Clinical Interview for DSM-5-Disorders Clinician Version (SCID-5/CV) to the Turkish Language. Turk Psikiyatri Derg. 2019 Spring;30(1):51-56.

First MB, Williams JBW, Karg, RS, Spitzer, RL. Structured Clinical Interview for DSM-5: Research Version. Arlington, VA: American Psychiatric Association; 2015.

Fujii Y, Kitagawa N, Shimizu Y, Mitsui N, Toyomaki A, Hashimoto N, Kako Y, Tanaka T, Asakura S, Koyama T, Kusumi I. Severity of generalized social anxiety disorder correlates with low executive functioning. Neurosci Lett. 2013; 543:42-6.

Heaton RK, Chelune GJ, Talley JL, Kay GG, Curttis CG. Wisconsin card sorting test manual: Revised and expanded. Psycological Assesment Resources. Florida. 1993.

Karakas S, Kafadar H. Neuropsychological Tests in the Assessment of Cognitive Processes in Schizophrenia: Measuring Memory and Attention. Turkish Psychiatry Index 1999; 2(4):132-52.

Karakas S. BİLNOT Bataryası El Kitabı: Research and Development Studies for Neuropsychological Tests. 2nd Edition. Eryilmaz Offset. Ankara. 2006.

Kim J, Gorman J. The psychobiology of anxiety. Clinical Neuroscience Research, 2005, Volume 4, 335-347. 
Kortte KB, Horner MD, Windham WK. The trail making test, part B: cognitive flexibility or ability to maintain set? Appl Neuropsychol, 2002; 9(2):106-9.

Marcin MS, Nemeroff CB. The neurobiology of social anxiety disorder: The relevance of fear and anxiety, Acta Psychiatry Scand, 2003; 108 (Suppl. 417), 51-64.

Oner N, Le Compte A. State Trait Anxiety Inventory Handbook, Second Edition, Bogazici University Press.İstanbul.1985.

Potts NL, Davidson JR, Krishnan KR, Doraiswamy PM. Magnetic resonance imaging in social phobia. Psychiatry Res. 1994; 52(1):35-42.

Reitan RM. Validity of the trail making test as an indication of organic brain damage. Percept Mot Skills. 1958; 8:271-276.

Sachs G, Anderer P, Margreiter N. P300 event-related potentials and cognitive function in social phobia. Psychiatry Res. 2004; 131(3):249-61.

Sutterby SR, Bedwell JS. Lack of neuropsychological deficits in generalized social phobia. PLoS One 2012; 7(8):e42675.

Syal S, Hattingh CJ, Fouche JP, Spottiswoode B, Carey PD, Lochner C, Stein DJ. Grey matter abnormalities in social anxiety disorder: a pilot study. Metab Brain Dis 2012; 27:299-309.

Tiihonen J, Kuikka J, Bergstrom K, Lepola U, Koponen H, Leinonen E.Dopamine reuptake site densities in patients with social phobia. Am J Psychiatry. 1997;154(2):239-42.

Tillfors M, Furmark T, Marteinsdottir I, Fischer H, Pissiota A, Långstrom B, Fredrikson M. Cerebral blood flow in subjects with social phobia during stressful speaking tasks: a PET study. Am J Psychiatry 2001;158(8):1220-6.

Topcuoğlu V, Fistıkcı N, Ekinci O, Gonentur A, Comert B, Agouridas BC. Assessment of Executive Functions in Social Phobia Patients Using the Wisconsin Card Sorting Test. Turkish Journal of Psychiatry 2009; 20(4):322-331.

Wenzel A, Holt CS. Memory bias against threat in social phobia. Br J Clin Psychol. 2002; 41(1):7379.

Williams JMG, Watts FN, MacLeod C, Mathews A. Cognitive Psychology and Emotional Disorders. İkinci bask1, Chicester, Wiley, 1997.

Yazıcı MK, Demir B, Tanriverdi N, Karaagaoglu E, Yolac P. Hamilton Anxiety Rating Scale: Interrater reliability and validity study. Turkish Journal of Psychiatry,1998; 9(2):114-120. 